\title{
Pengukuran Kualitas Hidup Pasien Program Pengelolaan Penyakit Kronis Diabetes Melitus Tipe 2 di Puskesmas Tamalanrea Makassar
}

\author{
Fajriansyah $^{1,3,4^{*}}$, Keri Lestari ${ }^{1,3}$, Aulia Iskandarsyah ${ }^{2}$, Irma M. Puspitasari ${ }^{1,3}$ \\ ${ }^{1}$ Departemen Farmakologi dan Farmasi Klinik, Fakultas Farmasi Universitas Padjadjaran \\ ${ }^{2}$ Departemen Psikologi Klinis, Fakultas Psikologi Universitas Padjadjaran \\ ${ }^{3}$ Pusat Unggulan IPTEK-PT Inovasi Pelayanan Kefarmasian Universitas Padjadjaran Centre of Excellence for \\ Pharmaceutical Care Innovation \\ ${ }^{4}$ Bagian Farmakologi dan Farmasi Klinik, Akademi Farmasi Kebangsaan Makassar \\ *Email korespondensi: fajriansyah.fajrin@yahoo.com
}

(Submit 15/03/2019, Revisi 05/09/2019, Diterima 20/12/2019)

\begin{abstract}
Abstrak
Diabetes Melitus Tipe 2 (DMT2) memiliki dampak yang kuat terhadap kualitas hidup pasien. Program Pengelolaan Penyakit Kronis (PROLANIS) merupakan suatu sistem pelayanan kesehatan dan pendekatan proaktif yang dilaksanakan secara terintegrasi yang melibatkan peserta, fasilitas kesehatan dan BPJS Kesehatan dalam rangka pemeliharaan kesehatan bagi peserta BPJS Kesehatan. Penelitian ini bertujuan untuk mengukur kualitas hidup pasien PROLANIS DMT2 di Puskesmas Tamalanrea kota Makassar. Desain penelitian yang digunakan adalah observasional rancangan potong lintang dengan pengumpulan data dilakukan dengan pengisian kuesioner secara prospektif. Subjek penelitian adalah pasien PROLANIS DMT2 yang memenuhi kriteria inklusi dan eksklusi yang berobat di Puskesmas Tamalanrea periode Januari-Juni 2017. Kualitas hidup pasien diukur secara generik dengan menggunakan kuesioner Euro Quality of Life 5 Dimension 5 Level (EQ5D5L) Bahasa Indonesia. Analisis data setiap kondisi kesehatan menggunakan nilai indeks utilitas EQ5D5L Indonesia. Selanjutnya dihitung persentase masalah pasien, indeks utilitas dan nilai Visual Analogue Scale (VAS). Sebanyak 69 pasien bersedia berpartisipasi dalam penelitian ini. Diperoleh 39 nilai indeks status kesehatan EQ5D5L. Nilai indeks EQ5D5L tertinggi adalah 1,000 (10 pasien $14,49 \%$ ) dan nilai terendah adalah 0,035 (1 pasien 1,45\%). Rata-rata nilai indeks EQ5D5L adalah 0,609 $\pm 0,26$ dan rata-rata nilai VAS adalah 74,36 $\pm 14,60.10$ pasien (14,49\%) tidak memiliki masalah pada kelima dimensi, 51 pasien (73,91\%) bermasalah pada dimensi kemampuan berjalan, 46 pasien $(66,67 \%)$ bermasalah pada dimensi kegiatan yang biasa dilakukan, 45 pasien $(65,21 \%)$ bermasalah pada dimensi rasa cemas/depresi (sedih), 44 pasien $(63,77 \%)$ bermasalah pada dimensi rasa nyeri/tidak nyaman dan 42 pasien $(60,87 \%)$ bermasalah pada dimensi perawatan diri. Sehingga, kualitas hidup pasien PROLANIS DMT2 di Puskesmas Tamalanrea menunjukkan angka yang rendah.
\end{abstract}

Kata kunci: Diabetes Melitus Tipe 2, Prolanis, Kualitas Hidup, Puskesmas Tamalanrea 


\section{Outline}

- Pendahuluan

- Metode

- Hasil dan Pembahasan

- Kesimpulan

- Ucapan Terima Kasih

- Daftar Pustaka

\section{Pendahuluan}

Diabetes Melitus Tipe 2 (DMT2) adalah penyakit kronis akibat dari defisiensi metabolisme glukosa yang disebabkan oleh kekurangan sekresi insulin dari sel-sel beta pankreas ${ }^{1}$. Penyakit DMT2 menyertai penderitanya seumur hidup sehingga sangat mempengaruhi kualitas hidup penderita. Beberapa penelitian menyatakan bahwa hidup dengan diabetes mempunyai pengaruh negatif terhadap kualitas hidup penderita walaupun dengan atau tanpa komplikasi. Kualitas hidup merupakan istilah yang mengacu pada kepuasan hidup dan kesejahteraan subjektif (subjective wellbeing/SWB), dimana kata kebahagiaan dan kualitas hidup merujuk sebagai bagian pada kualitas kesadaran atau tingkat pengalaman dalam hidup yang positif2. Berdasarkan peryataan tersebut dapat diartikan bahwa kualitas hidup (Quality of Life) merupakan derajat kepuasan dan kesejahteraan subjektif yang dirasakan ataupun dialami secara positif.

Program Pengelolaan Penyakit Kronis (PROLANIS) adalah suatu sistem pelayanan kesehatan dan pendekatan proaktif yang dilaksanakan secara terintegrasi yang melibatkan peserta, fasilitas kesehatan dan Badan Penyelenggara Jaminan Sosial (BPJS) Kesehatan dalam rangka pemeliharaan kesehatan bagi peserta BPJS Kesehatan yang menderita penyakit kronis untuk mencapai kualitas hidup yang optimal dengan biaya pelayanan kesehatan yang efektif dan efisien. Sasaran dari kegiatan prolanis adalah seluruh peserta BPJS Kesehatan penyandang penyakit kronis khususnya DMT2 dan hipertensi ${ }^{3}$.

Salah satu Pusat Kesehatan Masyarakat yang memberikan pelayanan tersebut kepada pasien PROLANIS DMT2 di kota Makassar adalah Puskesmas Tamalanrea. Berdasarkan data yang diperoleh dari BPJS Kesehatan Kota Makassar bulan Desember Tahun 2016 menyatakan bahwa jumlah pasien PROLANIS DMT2 yang terdaftar di Puskesmas Tamalanrea sejumlah 71 orang. Penelitian ini bertujuan untuk mengukur kualitas hidup pasien PROLANIS DMT2 di Puskesmas Tamalanrea kota Makassar

\section{Metode}

\section{A. Metode}

Metode yang digunakan dalam penelitian adalah metode penelitian observasional rancangan potong lintang dengan pengumpulan data dilakukan dengan pengisian kuesioner secara prospektif. Penelitian ini telah diajukan di Komite Etik Penelitian Kesehatan Fakultas Kedokteran Universitas Hasanuddin dan telah disetujui dengan nomor rekomendasi persetujuan etik 146/H4.8.4.5.31/PP36-KOMETIK/2017. 


\section{B. Subjek}

Subjek dalam penelitian ini adalah pasien PROLANIS DMT2 yang berobat di Puskesmas Tamalanrea kota Makassar pada periode Januari-Juni 2017. Subjek penelitian dipilih menggunakan teknik total sampling. Kriteria inklusi yang ditetapkan dalam penelitian ini : Pasien terdaftar dalam program PROLANIS di BPJS Kota Makassar, usia 18 - 65 tahun, semua pasien DMT2 dengan atau tanpa penyakit penyerta dan bersedia mengikuti penelitian dengan menandatangani lembar persetujuan penelitian (informed consent). Kriteria eksklusi pada penelitian ini meliputi: pasien dengan jadwal kontrol tidak teratur atau tidak rutin (tidak setiap bulan kontrol), pasien dengan data rekam medik tidak lengkap, pasien dalam keadaan yang tidak memungkinkan untuk mengisi kuesioner (tidak dapat berbicara, melihat dan mendengar).

\section{Instrumen penelitian}

Bahan dan sumber data yang digunakan dalam penelitian ini yaitu data primer yang diperoleh dengan pengisian kuesioner oleh pasien dan data sekunder diperoleh dari rekam medik pasien. Proses pengumpulan data dilakukan dengan cara mewawancarai pasien dan menggunakan alat bantu berupa kuesioner yang diisi oleh pasien yang telah bersedia menjadi responden. Alat penelitian yang digunakan adalah lembar informed consent, lembar data diri pasien untuk memperoleh identitas, dan data sosiodemografi pasien, kuesioner Euro Quality of Life 5 Dimension 5 Level (EQ-5D-5L). Kuesioner EQ$5 \mathrm{D}-5 \mathrm{~L}$ bahasa Indonesia diperoleh dengan cara mengisi formulir registrasi melalui https://euroqol.org/registrationform/

\section{Analisis Data}

Kuesioner EQ-5D-5L terdiri dari 2 bagian yaitu sistem deskriptif dan Visual Analogue Scale (VAS). Bagian sistem deskriptif terdiri atas 5 dimensi yaitu dimensi mobilitas, dimensi perawatan diri, dimensi kegiatan biasa, dimensi nyeri/ketidaknyamanan dan dimensi kecemasan/depresi. Masing-masing dari 5 dimensi dibagi menjadi 5 tingkat dari masalah yang dirasakan yaitu tingkat 1 menunjukkan tidak ada masalah, tingkat 2 menunjukkan sedikit masalah, tingkat 3 menunjukkan masalah moderat, tingkat 4 menunjukkan masalah berat dan tingkat 5 menunjukkan masalah ekstrim. Setiap dimensi terdiri dari 5 digit nilai. Misalnya, nilai 11111 menunjukkan tidak ada masalah pada salah satu dari 5 dimensi, sedangkan nilai 12345 menunjukkan tidak ada masalah dengan mobilitas, sedikit masalah dengan perawatan diri, masalah moderat dengan melakukan kegiatan yang biasa, masalah berat pada nyeri atau ketidaknyamanan dan masalah ekstrim pada kecemasan atau depresi4,5. Selanjutnya, nilai status kondisi kesehatan dikonversi dengan menggunakan nilai utilitas Indonesia ${ }^{6}$. Sedangkan untuk Visual Analogue Scale (VAS) terdiri dari skala 0 sampai 100. Semakin tinggi nilai skala yang dihasilkan maka semakin baik kondisi kesehatan, dan sebaliknya semakin rendah skala yang dihasilkan maka semakin buruk kondisi kesehatan ${ }^{4,5}$.

\section{Hasil dan Pembahasan}

\section{A. Hasil}

Sebanyak 69 pasien yang memenuhi kriteria inklusi bersedia berpartisipasi dalam penelitian ini. Sosiodemografi dan karakteristik klinis pasien PROLANIS DMT2 di Puskesmas Tamalanrea dapat dilihat pada tabel 1. 
Fajriansyah, dkk, Majalah Farmasetika, 4 (Suppl 1) 2019, 225 - 232

Tabel 1. Sosiodemografi dan karakteristik pasien

\begin{tabular}{|c|c|c|}
\hline Karakterisik & $n=69$ & Persentase (\%) \\
\hline \multicolumn{3}{|l|}{ Jenis kelamin } \\
\hline Laki-laki & 27 & 39,13 \\
\hline Perempuan & 42 & 60,87 \\
\hline \multicolumn{3}{|l|}{ Usia } \\
\hline$<50$ tahun & 3 & 4,34 \\
\hline 50-59 tahun & 32 & 46,38 \\
\hline 60-65 tahun & 34 & 49,28 \\
\hline \multicolumn{3}{|l|}{ Pekerjaan } \\
\hline Bekerja & 41 & 59,42 \\
\hline Tidak bekerja/pensiun & 28 & 40,58 \\
\hline \multicolumn{3}{|l|}{ Tingkat pendidikan } \\
\hline Sekolah Dasar & 37 & 53,62 \\
\hline Sekolah Menengah Pertama & 9 & 13,04 \\
\hline Sekolah Menengah Atas & 15 & 21,74 \\
\hline Universitas & 8 & 11,60 \\
\hline \multicolumn{3}{|l|}{ Pendapatan perbulan (Rp) } \\
\hline$<\mathrm{UMR}^{*}$ & 26 & 37,68 \\
\hline$>$ UMR & 43 & 62,32 \\
\hline \multicolumn{3}{|l|}{ Status perkawinan } \\
\hline Menikah & 64 & 92,75 \\
\hline Tidak menikah & 5 & 7,25 \\
\hline \multicolumn{3}{|l|}{ Durasi diabetes } \\
\hline$\leq 5$ tahun & 31 & 44,93 \\
\hline$>5$ tahun & 38 & 55,07 \\
\hline \multicolumn{3}{|l|}{ Dianosis lainnya } \\
\hline Hiperlipidemia & 11 & 15,94 \\
\hline Hipertensi & 53 & 76,81 \\
\hline Gagal jantung & 3 & 4,35 \\
\hline Tidak ada komorbiditas & 2 & 2,90 \\
\hline
\end{tabular}

Tabel 2. Status kesehatan EQ5D5L dan nilai utilitas pasien PROLANIS DMT2

\begin{tabular}{|c|c|c|c|c|c|c|c|}
\hline $\begin{array}{c}\text { Status } \\
\text { kesehatan }\end{array}$ & Utilitas & Jumlah & $\begin{array}{c}\text { Persentase } \\
\text { (\%) }\end{array}$ & $\begin{array}{c}\text { Status } \\
\text { kesehatan }\end{array}$ & Utilitas & Jumlah & $\begin{array}{c}\text { Persentase } \\
\text { (\%) }\end{array}$ \\
\hline 11111 & 1,000 & 10 & 14,49 & 22232 & 0,516 & 1 & 1,45 \\
\hline 11112 & 0,921 & 1 & 1,45 & 22233 & 0,461 & 5 & 7,25 \\
\hline 11122 & 0,835 & 2 & 2,90 & 22322 & 0,459 & 1 & 1,45 \\
\hline 11221 & 0,824 & 1 & 1,45 & 22333 & 0,395 & 1 & 1,45 \\
\hline 11222 & 0,745 & 3 & 4,35 & 23232 & 0,477 & 1 & 1,45 \\
\hline 12121 & 0,813 & 1 & 1,45 & 23233 & 0,422 & 1 & 1,45 \\
\hline 21111 & 0,881 & 1 & 1,45 & 23322 & 0,420 & 2 & 2,90 \\
\hline 21112 & 0,802 & 2 & 2,90 & 23332 & 0,411 & 1 & 1,45 \\
\hline 21121 & 0,795 & 2 & 2,90 & 23333 & 0,356 & 1 & 1,45 \\
\hline 21122 & 0,716 & 1 & 1,45 & 32232 & 0,443 & 1 & 1,45 \\
\hline 21211 & 0,791 & 2 & 2,90 & 32333 & 0,322 & 1 & 1,45 \\
\hline 21212 & 0,712 & 1 & 1,45 & 33223 & 0,358 & 2 & 2,90 \\
\hline 21222 & 0,626 & 1 & 1,45 & 33322 & 0,347 & 1 & 1,45 \\
\hline 22111 & 0,780 & 2 & 2,90 & 33332 & 0,338 & 1 & 1,45 \\
\hline 22112 & 0,701 & 1 & 1,45 & 33333 & 0,283 & 4 & 5,80 \\
\hline 22211 & 0,690 & 4 & 5,80 & 33334 & 0,190 & 2 & 2,90 \\
\hline 22212 & 0,611 & 1 & 1,45 & 33344 & 0,087 & 1 & 1,45 \\
\hline 22222 & 0,525 & 2 & 2,90 & 33433 & 0,138 & 1 & 1,45 \\
\hline 22223 & 0,470 & 1 & 1,45 & 33443 & 0,035 & 1 & 1,45 \\
\hline 22231 & 0,595 & 1 & 1,45 & Rata-rata & $0,609 \pm 0,26$ & & \\
\hline
\end{tabular}


Karakteristik sosiodemografi berdasarkan jenis kelamin perempuan lebih banyak menderita DMT2 yaitu 42 pasien (60,87\%). Hal ini sejalan dengan RISKESDAS (2013) yang menyatakan prevalensi diabetes berdasarkan diagnosis dokter dan gejala lebih banyak pada perempuan dan meningkat sesuai dengan bertambahnya umur ${ }^{7}$. Usia pada rentang 60-65 tahun lebih besar yaitu 34 pasien (49,28\%). Bekerja lebih besar yaitu 41 pasien $(59,42 \%)$. Tingkat pendidikan Sekolah Dasar lebih besar yaitu 37 pasien $(53,62 \%)$. Pendapatan perbulan $>$ UMR lebih besar yaitu 43 pasien $(62,32 \%)$. Status perkawinan menikah lebih besar yaitu 64 pasien (92,75\%). Durasi diabetes rentang waktu $>5$ tahun lebih besar yaitu 38 pasien $(55,07 \%)$. Kemudian gambaran mengenai diagnosis penyakit lainnya yang dialami pasien, penyakit hipertensi lebih besar yaitu 53 pasien $(76,81 \%)$. Hipertensi berhubungan erat dengan diabetes melitus. Gibney (2009) menyebutkan bahwa hipertensi merupakan faktor risiko utama untuk terjadinya diabetes melitus. ${ }^{8}$ Hubungannya dengan DMT2 sangatlah kompleks, hipertensi dapat membuat sel tidak sensitif terhadap insulin (resisten insulin) ${ }^{9}$.

Tabel 3. Nilai Visual Analogue Scale (VAS) pasien PROLANIS DMT2

\begin{tabular}{|c|c|c|}
\hline EQ VAS & $\begin{array}{c}\text { Jumlah } \\
\mathrm{n}=69\end{array}$ & $\begin{array}{c}\text { Persentase } \\
(\%)\end{array}$ \\
\hline 100 & 6 & 8,70 \\
\hline 95 & 2 & 2,90 \\
\hline 90 & 5 & 7,25 \\
\hline 89 & 1 & 1,45 \\
\hline 88 & 1 & 1,45 \\
\hline 87 & 1 & 1,45 \\
\hline 86 & 2 & 2,90 \\
\hline 85 & 4 & 5,80 \\
\hline 82 & 1 & 1,45 \\
\hline 80 & 7 & 10,14 \\
\hline 78 & 1 & 1,45 \\
\hline 75 & 4 & 5,80 \\
\hline 70 & 7 & 10,14 \\
\hline 69 & 1 & 1,45 \\
\hline 66 & 1 & 1,45 \\
\hline 65 & 6 & 8,70 \\
\hline 60 & 11 & 15,94 \\
\hline 55 & 4 & 5,80 \\
\hline 50 & 4 & 5,80 \\
\hline Rata-rata & $74,36 \pm 14,60$ \\
\hline
\end{tabular}

Tabel 4. Persentase tingkat masalah pasien PROLANIS DMT2 pada domain EQ5D5L

\begin{tabular}{|l|l|c|c|}
\hline \multicolumn{1}{|c|}{$\begin{array}{c}\text { Domain } \\
\text { EQ5D5L }\end{array}$} & Jumlah & $\begin{array}{c}\text { Persentase } \\
\text { (\%) }\end{array}$ \\
\hline Kemampuan berjalan & Tidak bermasalah & 18 & 26,09 \\
\hline & Bermasalah & 51 & 73,91 \\
\hline Perawatan diri & Tidak bermasalah & 23 & 33,33 \\
\hline Kegiatan yang biasa dilakukan & Bermasalah & 46 & 66,67 \\
\hline & Tidak bermasalah & 24 & 34,78 \\
\hline & Bermasalah & 45 & 65,21 \\
\hline Rasa nyeri/tidak nyaman & Tidak bermasalah & 25 & 36,23 \\
\hline Rasa cemas/depresi (sedih) & Bermasalah & 44 & 63,77 \\
\hline & Tidak bermasalah & 27 & 39,13 \\
\hline & Bermasalah & 42 & 60,87 \\
\hline
\end{tabular}




\section{B. Pembahasan}

World Health Organization (WHO) mendefenisikan kondisi sehat sebagai keadaan dimana "sempurna" secara fisik, mental maupun kesejahteraan sosial, tidak hanya diukur berdasarkan ada atau tidaknya penyakit, namun kondisi kesejahteraan individu tersebut perlu diperhatikan. Oleh sebab itu dalam melakukan pengukuran efektivitas perawatan, tidak hanya mengukur perubahan dalam frekuensi dan keparahan penyakitnya saja. Namun aspek well-being para pasienpun perlu diperhatikan. Untuk menaksir kondisi kesejahteraan pasien, dapat diketahui dengan melakukan pengukuran terhadap kualitas hidup ${ }^{10}$.

Utilitas adalah suatu ekspresi kuantitatif dari preferensi individu untuk mencapai suatu kondisi kesehatan (particular health state) pada kondisi ketidakpastian (uncertainty). Skor utilitas dibutuhkan agar dapat merefleksi preferensi atas status kesehatan yang mencerminkan juga efek peningkatan status kesehatan karena efikasi suatu intervensi/ obat serta efek samping yang terjadi ${ }^{11}$. Pada tabel 2 menunjukkan sebanyak 69 nilai indeks utilitas pasien PROLANIS DMT2. Nilai indeks utilitas EQ5D5L tertinggi adalah 1,000 dengan jumlah 10 pasien $(14,49 \%)$ dan nilai terendah adalah 0,035 dengan jumlah 1 pasien $(1,45 \%)$. nilai utilitas EQ5D5L memiliki rata-rata 0,609.

Visual analog scale atau VAS merupakan suatu pendekatan dengan cara memberikan pilihan rentang angka untuk menentukan status kesehatan seseorang pada saat itu. Pertanyaan yang dapat digunakan adalah "Bagaimana kualitas hidup Anda hari ini?". Penilaian ini menggunakan skala 0 sampai 100, dimana 100 berarti kesehatan terbaik yang dapat dibayangkan oleh pasien, dan 0 berarti kesehatan terburuk yang dapat dibayangkan oleh pasien. Pada tabel 3 dapat dilihat bahwa nilai EQ VAS tertinggi adalah 100 dengan jumlah 6 pasien $(8,70 \%)$ dan nilai EQ VAS terendah adalah 50 dengan jumlah 4 pasien (5,80\%). Nilai EQ VAS memiliki rata-rata 74,36 .

PROLANIS merupakan sistem pelayanan kesehatan dan pendekatan proaktif yang dilaksanakan secara terintegrasi yang melibatkan peserta, fasilitas kesehatan dan BPJS Kesehatan dalam rangka pemeliharaan kesehatan bagi peserta BPJS Kesehatan yang menderita penyakit kronis untuk mencapai kualitas hidup yang optimal ${ }^{3}$. Namun berdasarkan hasil penelitian ini, pasien PROLANIS DMT2 umumnya memiliki masalah pada kelima dimensi EQ5D5L (tabel 4). Dimensi yang paling bermasalah yaitu dimensi kemampuan berjalan dengan hasil 51 pasien $(73,91 \%)$, kemudian dimensi perawatan diri 46 pasien $(66,67 \%)$, dimensi kegiatan yang biasa dilakukan 45 pasien $(65,21 \%)$, dimensi rasa nyeri/tidak nyaman 44 pasien $(63,77 \%)$ dan dimensi rasa cemas/depresi/sedih 42 pasien $(60,87 \%)$. Hal ini sejalan dengan penelitian yang dilakukan oleh Grandy dkk yang menyatakan bahwa pasien dengan diabetes tipe 2 melaporkan tingkat kesulitan tertinggi dengan mobilitas, perawatan diri, dan melakukan kegiatan biasa. Proporsi yang serupa (> 60\%) pasien dengan diabetes tipe 2 dilaporkan mengalami rasa sakit atau tidak nyaman serta tingkat kegelisahan dan depresi yang tinggi ${ }^{12}$.

Faktor yang menyebabkan kualitas hidup pasien rendah karena penyakit diabetes dan komplikasi penyakit yang diderita oleh pasien. Hal ini sejalan dengan penelitian yang dilakukan oleh Pusat Pengendalian dan Pencegahan Penyakit diabetes melitus di Amerika menyatakan bahwa diabetes dan komplikasinya serta komorbiditas secara substansial mempengaruhi kualitas hidup terkait kesehatan pasien ${ }^{13}$. Kebanyakan 
pasien PROLANIS DMT2 mengalami komplikasi penyakit hipertensi $(76,81 \%)$ dan hiperlipidemia (15,94\%). Selain itu, pola hidup pasien yang kurang terkontrol juga mempengaruhi kualitas hidup pasien. Hal ini sejalan dengan penelitian yang dilakukan oleh Moreno dkk menyatakan bahwa gaya hidup yang tidak sehat diakui akan memberikan kualitas hidup yang buruk ${ }^{14}$. Kebanyakan peserta PROLANIS yang kondisinya tidak terkontrol adalah mereka yang sudah cukup tua dan/atau tidak memiliki kerabat atau keluarga yang dapat mengantarnya berkunjung ke Puskesmas untuk memeriksakan status kesehatan dan mengikuti PROLANIS secara berkesinambungan. Dilain sisi, faktor yang menyebabkan kualitas hidup pasien rendah mungkin juga dikarenakan kurang optimalnya PROLANIS, terbukti pada saat pengambilan data dilapangan, beberapa pasien PROLANIS DMT2 yang berkunjung ke Puskesmas hanya untuk periksa ke dokter dan mengambil obat tanpa mau mengikuti senam dan edukasi. Program PROLANIS yang telah berjalan di Puskesmas Tamalanrea adalah aktifitas konsultasi medis/edukasi dan aktifitas klub. Untuk program home visit dan reminder belum berjalan optimal dikarenakan keterbatasan sumber daya manusia, dana dan waktu.

\section{Kesimpulan}

Kualitas hidup pasien PROLANIS DMT2 di Puskesmas Tamalanrea menunjukkan angka yang rendah.

\section{Ucapan Terima Kasih}

Terima kasih kepada Kementerian Riset, Teknologi dan Pendidikan Tinggi Republik Indonesia yang mendanai penelitian ini, dan juga terima kasih kepada pasien yang telah bersedia menjadi subjek dalam penelitian ini.

\section{Daftar Pustaka}

1. Kemienski, M. and Koegh, J. 2015, Pharmacology Demistified. Rapha Publishing. Yogyakarta.

2. Frisch, Michael B. 2006. Quality of Life Therapy: Applying a Life Satisfaction Approach to PositivePsychology and Cognitive Therapy. New Jersey: John Wiley and Sons, Inc.

3. Idris, F. 2014. Panduan Praktis PROLANIS (Program Pengelolaan Penyakit Kronis). Jakarta:BPJS.

4. EoroQol Group., 1990, EuroQol - a new facility for the measurement of healthrelated quality of life (Electronic version). Health Policy, 16(3), 199-208.

5. EoroQol Group., 2011, EQ-5D-3L User Guide Basic Information on how to use the EQ-5D-3L instrument Version 4.0April 2011, EuroQol Group Executive Office On behalf of the EuroQol Group.

6. Purba, Fredrick \& Hunfeld, Joke \& Iskandarsyah, Aulia \& Fitriana, Titi \& Supardi Sadarjoen, Sawitri \& Ramos-Goñi, J \& Passchier, Jan \& Busschbach, J.J.V. (2017). The Indonesian EQ-5D-5L Value Set. PharmacoEconomics. 35. 10.1007/s40273-017-0538.

7. Kementerian Kesehatan RI. Riset Kesehatan Dasar (Riskesdas 2013). Jakarta: Badan Penelitian dan Pengembangan Kesehatan: 2013. 
8. Gibney MJ, Margetts BM, Kearney JM \& Arab L,eds 2004. Public Health Nutrition. The Nutrition Society Textbook Series. Oxford, UK, Blackwell Science Publishing.

9. Mihardja L. 2009. Faktor yang berhubungan dengan pengendalian gula darah pada penderita diabetes melitus di perkotaan indonesia. Majalah Kedokteran Indonesia. 59(9):23-31.

10. WHO, 1997, WHOQOL, Measuring Quality of Life, Programme on Mental Health, Division on Mental Health and Prevention of Substance Abuse, WHO, Geneva.

11. Kementerian Kesehatan RI:2017. Buku Penilaian Teknologi Kesehatan, Jakarta.

12. Grandy S, Fox KM. EQ-5D visual analog scale and utility index values in individuals with diabetes and at risk for diabetes: findings from the Study to Help Improve Early evaluation and management of risk factors Leading to Diabetes (SHIELD) Health Qual Life Outcomes. 2008;6;18. doi: 10.1186/1477-7525-618Centers for Disease Control and Prevention: Self-rated fair or poor health among adults with diabetes - United States, 1996-2005. MMWR 2006, 55: 12241227.

13. Moreno M, Pearson TA. The Quality of Lifestyle and the Quality of Life: Comment on "Lifestyle Factors on the Risks of Ischemic and Hemorrhagic Stroke". Arch Intern Med. 2011;171(20):1819-1820. doi:10.1001/archinternmed.2011.442. 